\title{
Octreotide treatment for neonatal chylothorax
}

\author{
Carlo Bellini $^{1} \cdot$ Laura Costanza De Angelis ${ }^{1} \cdot$ Tommaso Bellini $^{1}$
}

Received: 1 August 2018 / Accepted: 30 August 2018 / Published online: 14 September 2018

(c) Children's Hospital, Zhejiang University School of Medicine 2018

To the Editor,

We have read the interesting paper by Costa and Saxena entitled "Surgical chylothorax in neonates: management and outcomes", recently published in the World Journal of Pediatrics [1]. There are few points of the article that we would like to discuss. We recently published a systematic review focusing on the use of octreotide for congenital and acquired chylothorax in newborns [2]. Our review concluded that octreotide was safe and effective in the treatment of chylothorax in newborns, especially for the congenital forms, and that octreotide therapy should be considered as an adjunctive treatment in term and preterm neonates affected by congenital and acquired chylothorax. Costa and Saxena reported 12 further cases of acquired (post-surgical) chylothorax than those included in our review. It is reassuring that both articles $[1,2]$ obtained similar conclusions. The initial dose of octreotide varied from 0.5 to $10 \mu \mathrm{g} / \mathrm{kg} / \mathrm{h}$ [1] and from 0.3 to $15 \mu \mathrm{g} / \mathrm{kg} / \mathrm{h} \mathrm{[2]}$, and the maximum dose reported was 10 vs $7.5 \mu \mathrm{g} / \mathrm{kg} / \mathrm{h}$, respectively [1, 2]. Apart from slight dose differences, in our opinion lacking practical clinical meaning, what we consider very important is that both reviews $[1,2]$ concluded that octreotide treatment is safe and effective and that the observed (scarce) adverse effects are mild and transient and generally well tolerated and not requiring discontinuation of the treatment.

$\mathrm{We}$, as certainly Costa and Saxena, are aware that given the very low incidence and the heterogeneity of chylothorax in neonates, randomized controlled trials to clarify octreotide use appear to be quite unfeasible, even in multicentric settings. Thus, we feel that reporting cases of neonatal chylothorax should be encouraged. Two independent large reviews including a wide number of patients have agreed that the conclusions show the use of octreotide to be the best available tool for the treatment of chylothorax in the neonatal age.

Author contributions All authors contributed equally to the article. Full access to all of the data in the study is available and the authors take responsibility for the integrity of the data and the accuracy of the data analysis. All authors contributed to study concept and design, drafted the initial manuscript, and reviewed and revised the manuscript.

Funding No financial or nonfinancial benefits have been received or will be received from any party related directly or indirectly to the subject of this article.

\section{Compliance with ethical standards}

Ethical approval Not needed.

Conflict of interest The authors have no conflicts of interest relevant to this article.

\section{References}

1. Costa KM, Saxena AK. Surgical chylothorax in neonates: management and outcomes. World J Pediatr. 2018;14:110-5.

2. Bellini C, Cabano R, De Angelis LC, Bellini T, Calevo MG, Gandullia $\mathrm{P}$, et al. Octreotide for congenital and acquired chylothorax in newborns: a systematic review. J Paediatr Child Health. 2018;54:840-7.
Carlo Bellini

carlobellini@gaslini.org

1 Neonatal Intensive Care Unit, Neonatal Emergency Transport Service, Department of Intensive Care, IRCCS Gaslini, Largo G. Gaslini 5, 16147 Genoa, Italy 